\title{
Comment
}

\section{Educação Emocional, Nova Maneira de Ensinar e de Aprender}

\author{
Marcio Moreira da Silva ${ }^{1}$
}

Resumo: O presente artigo discorre sobre o conceito de Educação Emocional de Mayer e Salovey, de 1990. Trata-se de uma estratégia educacional que, parece surgir como resposta às novas demandas educativas. Discorreremos de maneira breve, sobre conceitos de Educação, de emoções, de Educação Emocional, e por último, sobre os possíveis impactos dessa forma de educar, para a prática docentes. É possível que este novo arcabouço teórico-metodológico e prático promova de alguma forma, mudanças nas relações interpessoais no contexto de sala de aula.

Palavras Chave: Educação. Educação Emocional. Emoções

\section{Emotional Education, a New Way of Teaching and Learning}

\begin{abstract}
This article discusses the concept of Emotional Education of Mayer and Salovey, of 1990. It is an educational strategy that seems to arise in response to the new educational demands. We will briefly discuss concepts of Education, Emotions, Emotional Education, and lastly, about the possible impacts of this way of educating teachers. It is possible that this new theoretical-methodological and practical framework promotes in some way, changes in the interpersonal relations in the context of the classroom.
\end{abstract}

Keywords: Education. Emotional Education. Emotions

\section{Introdução}

O que vem a ser educação? Qual a finalidade dela? Segundo Petry (2002), o termo educação é proveniente do latim educare que significa ato de criar, de alimentar, ou ainda considerando-se que se trata de um verbo, conduzir para fora, indicando assim uma ação. Para Libâneo (1985) significa conduzir de um estado a outro. Em todo ato pedagógico há três componentes, um agente, uma mensagem a ser transmitida, e um educando. $\mathrm{O}$ agente trata-se de alguém ou grupo, etc. A mensagem refere-se aos conteúdos, os métodos, habilidades, etc. E por fim o educando que vai do indivíduo ao grupo.

\footnotetext{
${ }^{1}$ Mestrando em Educação pela Unisullivan University. Bacharel em Psicologia pela UNILEÃO Centro Universitário. Especialista em Psicologia Aplicada à Educação pela Universidade Regional do Cariri (URCA). Endereço para correspondência: Rua Nossa Senhora do Carmo, 140, Franciscanos - CEP: 63020-180, Juazeiro do Norte -CE. E-mail: marciopsi@bol.com.br
} 
A educação possui diversas categorias ou finalidades: Pode ser formal ou informal, a primeira sendo a escolar e a informal podendo ocorrer na família, através da internet, etc.

Em relação à finalidade, de acordo com Chabot e Chabot (2005) durante séculos a educação formal nas escolas esteve voltada para a transmissão de conteúdos voltados para as competências cognitivas e técnicas. Segundo Aranha (2006) a finalidade varia dependendo dos tempos históricos, considerando-se os aspectos sociais. Um cidadão na Grécia Homérica era formado para ser guerreiro. Em Esparta para a formação militar. Em Atenas para a cidadania, na Idade Média formava-se para os valores religiosos, etc. Os tempos mudam e surgem novas necessidades. Além dessas finalidades, pode ser voltadas para conteúdos específicos como ambiental, inclusiva, à distância, etc.

Neste sentido este artigo teve como finalidade apresentar uma categoria surgida das novas necessidades da sociedade, a da educação emocional, que ganhou destaque nas últimas décadas do século XX, advindas das descobertas das neurociências principalmente nos escritos de António Damásio com o surgimento de teorias psicológicas como as das inteligências múltiplas de Howard Gardner, além da teoria da Inteligência emocional, baseadas nos modelos propostos por Salovey e Mayer, Goleman e Bar-On.

Esse artigo foi constituído de pesquisa bibliográfica, baseada em dados oriundos de livros, revistas e artigos científicos que também foram publicados na internet. Neste artigo, buscamos nas fontes de autores como Alzina, Chabot e Chabot, Fernandéz-Berrocal, dentre outros que trabalham com o conceito.

\section{As emoções}

Qual a importância das emoções? Quem nos responde a isso é Damásio (2012) ao afirmar que independente de serem positivas ou negativas, as emoções são necessárias no que diz respeito à nossa sobrevivência e adaptação ao meio. Elas fazem parte do cotidiano de todas as pessoas, assim como no universo escolar e do aprendizado.

De acordo com Muniz (2012) as emoções são: 
“[...] eventos psicológicos de experiências introspectivas, caracterizadas pela qualidade, intensidade e sensação, que o inerente prazer ou desprazer provoca a pessoa a agir de maneira característica. As emoções, normalmente, envolvem mudanças corporais e cognitivas internas e externas no aprendente." (MUNIZ, 2012, p. 152)

Segundo a autora citada as emoções podem causar prazer ou desprazer, levando a um tipo de ação própria de cada emoção. A autora reconhece que as emoções se manifestam através das mudanças corporais, dentre elas podemos citar as expressões faciais, estudadas por Paul Ekman, psicólogo norte-americano. Há também as mudanças cognitivas que fazem as interpretações das situações que ocorrem tanto internamente como externamente, de maneira a identificar se aquela situação cuja emoção provocou é boa ou ruim. Percebe-se, portanto que as emoções ocorrem da relação do sujeito com o ambiente e das interpretações cognitivas que ele faz das situações que ocorrem desse contato.

Dessa forma, Alzina (2003) afirma que a emoção é produzida por informações sensoriais, que chegam aos centros emocionais do cérebro, havendo respostas neurofisiológicas, passando pelo neocórtex onde há a interpretação da informação. Assim as emoções são geradas a partir de acontecimentos internos ou externos.

Com esse breve discorrer sobre as emoções, desenvolveremos a seguir o conceito de Educação Emocional.

\section{A Educação Emocional}

Como Aranha afirma (1996) a finalidade da educação está baseada em necessidades sociais de cada época. Durante os séculos e de maneira particular no século XX, as pessoas se definiam como seres racionais. Isso tem mudado a partir do final do século passado e início deste século XXI. A dicotomia razão versus emoção tem perdido sua força. Damásio neurocientista português, conhecido pela obra "O erro de Descartes", trata da relação entre emoções e sentimentos e de seus alicerces cerebrais. Com a teoria da inteligência emocional de Salovey e Mayer esse novo olhar sobre as emoções é complementado.

Para Alzina (2006, 2003,2012, 2017) a educação emocional surge num contexto de que a educação formal predominantemente pautada nos conteúdos cognitivos, não conseguiu 
responder satisfatoriamente a situações tais como: problemas de convivência, fracasso escolar, indisciplina, prevenção do consumo de drogas, estresse, depressão, ansiedade, violência, etc. Surge como uma educação preventiva sobre todos os aspectos citados, não pretendendo ser a tábua de salvação da educação. Mas, do que se trata a Educação Emocional? Alzina (2003) a define como:

“... um processo educativo contínuo e permanente, que pretende promover o desenvolvimento de competências emocionais, como um elemento essencial do desenvolvimento integral da pessoa, com o objetivo de capacitar para a vida. Tudo isto tem como finalidade aumentar o bem-estar pessoal e social." (ALZINA, 2003, p.27).

O autor afirma que a educação das emoções deve ser um processo contínuo e permanente, começando na infância, tornando-se continuada durante toda a vida. De forma a conduzir o educando para o desenvolvimento dessas competências, reconhecidas como essenciais no desenvolvimento da personalidade, favorecendo o bem-estar tanto nas esferas intrapessoais como nas interpessoais. Trata-se de uma educação que perpassa as esferas formais e informais. Ela deve estar presente na família, estendendo-se à escola.

Segundo Torres (2008) existem diversos programas e currículos de educação emocional pelo mundo, todos voltados para as competências emocionais, mas, a raiz desses trabalhos está voltada para o conceito de Inteligência Emocional, proposta por Mayer e Salovey (1997) de reconhecer e expressar nossas emoções, a habilidade para compreender as próprias emoções e dos outros e regular as próprias emoções, no intuito de favorecer o crescimento emocional e intelectual. Ainda em relação aos conteúdos Alzina (2005) afirma que variam de acordo com o nível educativo dos alunos, considerando os conhecimentos prévios sobre o assunto, maturidade, etc. Porém a temática deve incluir o conceito de emoções, sentimentos, afeto, deve considerar também as positivas, as negativas, emoções primárias e secundárias, a natureza da Inteligência Emocional, observando-se que a educação emocional é de metodologia prática, incluindo dinâmicas de grupo, jogos, autorreflexão, etc. Alzina (2011) ainda reitera a necessidade de se entender as emoções e como elas afetam desde nosso comportamento até nossa saúde.

De acordo com o conceito de Inteligência Emocional de Mayer e Salovey (1990) e suas divisões, Alzina (2003, 2006, 2012,2017) reconhece que a educação emocional tem como objetivo fazer com que os educandos possam ter: consciência de suas emoções, isto é, 
conhecer as próprias e identificar as dos outros, para dessa forma poder nomeá-las corretamente.

Sobre ter consciência das emoções, Chabot e Chabot (2005), Del Prette e Del Prette (2005) reconhecem sua importância. Identificar emoções na infância como raiva, tristeza, alegria, medo, vergonha, e nomeá-las, ajudam as crianças no controle e na expressão adequada dos aspectos emocionais. Portanto conhecer suas emoções e as dos outros ajudará a criança a lidar com elas, facilitará nas relações interpessoais e na maneira correta de expressar as emoções.

De acordo com Chabot e Chabot (2005) expressar as emoções admite expressar as próprias e ajudar os outros a fazerem-na de maneira adequada. Tem como pré-requisito o conhecer e reconhecer as emoções. Existem pessoas que são incapazes de reconhecê-las e tão pouco expressa-las, sofrem de Alexitimia. Quando as emoções são reprimidas e não se consegue expressa-las verbalmente, identificam-se distúrbios emocionais e psicossomáticos.

Como afirmam Ramos (2006) e Chabot e Chabot (2005) expressar as emoções é saudável, não expressa-las causa sofrimento físico e mental. Dessa maneira Del Prette e Del Prette (2005) incentivam que as crianças possam conversar sobre suas emoções, positivas ou negativas com os pais, e estes devem ter uma postura de validamento das emoções, sendo empáticas, não negando ou ridicularizando aquilo que elas estão sentindo.

Além disso, Alzina $(2003,2006,2012,2017)$ afirma que faz parte da educação emocional desenvolver a habilidade de regular as próprias emoções, adquirir tolerância à frustração, prevenir-se dos efeitos negativos de algumas emoções; desenvolver habilidades para gerar emoções positivas; desenvolver a habilidade de se motivar; adotar atitudes positivas perante a vida, etc.

Também a motivação, que tem ligação direta com as emoções, objetivando atividades produtivas gerando autonomia pessoal. Acrescentam-se ainda as habilidades socioemocionais, que são de suma importância nas relações interpessoais, principalmente no que diz respeito ao trabalho em grupo. Deve-se considerar também a emoção e o bem-estar subjetivo, como também o conceito de Flow (fluir) que diz respeito a um conceito presente como construto na Psicologia Positiva, vindo a complementar o tema do bem-estar. 


\section{Educação emocional e os docentes}

Para Santomé (2013) a formação dos professores não deve ser reduzida aos conteúdos culturais das diferentes disciplinas, assim como áreas do conhecimento e suas dimensões didáticas, há que se ater aos aspectos emocionais, principalmente da empatia, de forma a poder melhorar a relação professor-aluno.

Torres (2008) acredita que a educação emocional docente seja fator chave para a melhor convivência em sala de aula. Essa formação deve ter como conteúdos o conceito de emoção e das competências emocionais, tanto em nível de educação primária, como secundária. Isto por que, segundo Extremera e Fernández-Berrocal (2004) os professores são modelo adulto a ser seguido pelos alunos, de maneira mais específica quando do ensino primário, de maneira a modelar e ajustar o nível afetivo e emocional de seus alunos.

Dessa forma é defendida a formação inicial e permanente por vários autores Palomera, Fernández-Berrocal e Brackett (2008), Fernández-Berrocal e Ruiz-Aranda (2010), Alzina e Escoda (2012), por serem agentes do desenvolvimento emocional dos alunos.

Alzina (2017) reconhece que geralmente não há formação de professores em educação emocional, assim como também há a necessidade de que a família a tenha, o que os faz ser os primeiros que precisam aprender essas competências que posteriormente serão ensinadas aos filhos e na escola para os alunos, respectivamente. Da mesma forma Fernández-Berrocal, Ruiz-Aranda e Cabello (2010), reconhecem que existem poucos programas desse tipo de educação, acrescentando que os benefícios recaem sobre os professores e sobre sua prática docente, atingindo os alunos.

Fernández-Berrocal e Pacheco (2005) afirmam que reconhecer suas próprias emoções e as dos outros implica ter atenção e decodificar os sinais que aparecem nas expressões faciais, nos movimentos corporais e tom de voz. Isso favorece aos docentes no reconhecimento das emoções dos alunos, de maneira que ao perceberem os conteúdos emocionais apresentados nos semblantes dos seus alunos, se estão aborrecidos, tristes, alegres, sem entender o conteúdo ministrado, podendo oferecer a eles a escuta acerca de quaisquer problemas, proporcionado compreensão e apoio ao discente.

Os professores podem criar atividades de educação emocional, ou recorrer a publicações. Citamos algumas das atividades de reconhecimento de emoções, nomeações e 
que ajudam a falar sobre elas encontram-se em Del Prette e Del Prette (2005) como a caixinha de sentimentos, os sentimentos tem cores e eu tenho sentimentos. Outra obra são as atividades para o desenvolvimento da inteligência emocional das crianças de Alzina et al (2009).

Para Alzina (2011) algumas técnicas podem ser utilizadas de maneira a promover o desenvolvimento e a regulação emocional, tais como: relaxamento, meditação, respiração consciente, diálogo interno, controle do estresse, etc.

Finalmente em relação à formação permanente e contínua dos professores acerca da educação emocional, Alzina (2005) orienta que o conteúdo comece com os conceitos de emoção, seus tipos, sobre o cérebro emocional, as emoções e sua influência na saúde, a teoria das inteligências múltiplas de Gardner, sobre a inteligência emocional, considerando as divisões que incluem a consciência emocional, a regulação, bem-estar subjetivo, conceito de flow (fluir) e as aplicações da educação emocional. A metodologia é prática se dá através de diversas dinâmicas de grupo.

\section{Considerações finais}

A educação possui diversas categorias ou finalidades, podendo ser: Educação Inclusiva, Educação à Distância, etc. Neste artigo, descrevemos a categoria Educação Emocional, por ter se destacado no final do século XX através das descobertas das neurociências e de novas teorias como a da Inteligência Emocional. Chegou-se à conclusão de que apenas uma educação voltada para conteúdos de caráter racional não estava mais conseguindo responder às demandas que a escola estava recebendo, portanto surge uma nova categoria com o objetivo de educar aquela parte que vinha ficando à margem na educação.

As emoções são de suma importância no aprendizado, nas relações interpessoais, assim como intrapessoais. Com isso a Educação Emocional tem como objetivo permitir que através das divisões propostas pela Inteligência Emocional, o sujeito possa reconhecer suas emoções e as dos demais, a ao invés de reprimi-las, possa as expressar de maneira saudável, possa ainda desenvolver a capacidade de regulá-las, promovendo emoções favoráveis, lidando melhor e as aceitando. 
Por último, o aprendizado da Educação Emocional, ao começar na escola passa por uma formação inicial e continuada, considerando que este tipo de educação se dá por toda a vida. Através dos conteúdos focados na emoção, o docente não apenas repassa conteúdos aos discentes, mas ao incorporarem esses saberes, lidarão melhor através de uma relação pautada no afeto, favorecendo um ambiente educativo mais tranquilo, e como é objetivo da Educação Emocional, funcionar como prevenção a comportamentos inadequados.

\section{Referências}

ALZINA, Rafael. Educación emocional y competencias básicas para la vida. Revista de Investigación Educativa, 2003, Vol. 21, n. ${ }^{\circ}$ 1, págs. 7-43. Disponível em: http://revistas.um.es/rie/article/view/99071/94661 Acessado em: 09 Dez 2016.

Educación Emocional. Revista Padres y Maestros. Journal of Parents and

Teachers. $\quad \mathrm{N}^{\mathrm{O}} \quad 337 . \quad$ Febrero 2011. Disponível em:
http://revistas.upcomillas.es/index.php/padresymaestros/article/view/272. Acessado em: 20 Mar 2017.

La educación emocional en la formación del profesorado Revista Interuniversitaria de Formación del Profesorado, vol. 19, núm. 3, diciembre, 2005, pp. 95114. Disponível em: http://www.redalyc.org/pdf/274/27411927006.pdf. Acessado em 15 Fev.2017.

ALZINA, Rafael; PANIELLO, Silvia. Psicología positiva, educación emocional y el programa aulas felices. Papeles del Psicólogo / Psychologist Papers, 2017. Vol. 38(1), pp. 58-65. Disponível em: http://www.papelesdelpsicologo.es/pdf/2822.pdf. Acessado em: 20 Fev 2017.

ALZINA, Rafael et al. Atividades para o desenvolvimento da Inteligência Emocional em crianças. Editora ciranda cultural. 2009.

ARANHA, Maria. A Filosofia da Educação. $3^{\text {a }}$ ed. São Paulo: Editora Moderna, 2006.

DAMÁSIO, António. O erro de Descartes. Emoção, razão e o cérebro humano. $1^{\mathrm{a}}$ ed. Companhia das Letras, 2012.

FERNÁNDEZ-BERROCAL, Pablo, RUIZ-ARANDA, Desirée, CABELLO, Rosario, Docentes emocionalmente inteligentes Revista Electrónica Interuniversitaria de Formación del Profesorado [en linea] 2010, 13. Disponível em: <http://www.redalyc.org/articulo.oa?id=217014922005>. Acessado em 30 Jan. 2017. 
CHABOT, Daniel; CHABOT, Michel. Pedagogia Emocional. Sentir para aprender. Como incorporar a Inteligência Emocional às suas estratégias de ensino. Tradução: Diego Ambrosini e Juliana Montoia de Lima. Sá Editora. 2005.

EXTREMERA, Natalio; FERNÁNDEZ-BERROCAL, Pablo. La importancia de desarrollar la inteligencia emocional en el profesorado. 2004. Revista Iberoamericana de Educación. Disponível em: http://rieoei.org/deloslectores/759Extremera.PDF. Acessado em 25 Fev. 2017.

LIBÂNEO, José Carlos. Democratização da escola pública: a pedagogia crítico-social dos conteúdos. São Paulo, Loyola, 1985 (Educação I)

MUNIZ, Iana. A neurociência e as emoções do ato de aprender: quem não sabe sorrir, dançar e brincar e não deve ensinar. Itabuna, Bahia, 2012. Via Litterarum editora.

PALOMERA, Raquel; FERNÁNDEZ-BERROCAL, Pablo. \& BRACKETT, M. A. (2008). "La inteligencia emocional como una competencia básica en la formación inicial de los docentes: algunas evidencias". Revista Electrónica de Investigación Psicoeducativa, 15, 437-454. Disponível em: < http://www.investigacionpsicopedagogica.org/revista/articulos/15/espannol/Art_15_276.pdf>. Acesso em: 20 mar.2017.

PETRY, Ely. LDB - Lei de Diretrizes e Bases. Uma abordagem Orientadora. Age Editora. Porto Alegre, 2002.

RAMOS, Denise. A Psique do corpo. A dimensão simbólica da doença. Summus editorial. São Paulo, SP. $1^{a}$ reimpressão.

SANTOMÉ, Jurjo. Currículo escolar e justiça social. O cavalo de troia da educação. Tradução: Alexandre Salvaterra. 2013. Editora Penso.

TORRES, Ángeles. Educación emocional docente, factor clave para la mejora de la convivencia en el aula Disponível em: http://www.caib.es/sacmicrofront/archivopub.do?ctrl=MCRST151ZI113533\&id=113533. Acessado em: 01 Mar 2017.

Como citar este artigo (Formato ABNT):

SILVA, Marcio M. Educação Emocional, Nova maneira de Ensinar e de Aprender. Id on Line Revista Multidisciplinar e de Psicologia, Julho de 2017, vol.11, n.36, p.200-208. ISSN: 1981-1179.

Recebido: 27.06.2017

Aceito: 29.07 .2017 